\title{
ABSTRACTS FROM OTHER JOURNALS
}

\author{
PARAPLEGIA CAUSED BY SPINAL METASTASIS FROM THYROID \\ CANCER: Halnan, K. E. \& Roberts, P. H. (1967). Brit. med. F. 3, 534.
}

This is a report of nine cases of vertebral metastasis of thyroid cancer resulting in paraplegia. In some cases there was a goitre present for many years. In others removal of a benign thyroid tumour had been carried out several years before. Decompressive surgery is indicated in every case as soon as a transverse cord syndrome starts. The operation can be performed either trans-thoracally or by conventional laminectomy. Recovery of the paraplegia was achieved in five cases, in four of them the recovery was complete.

\section{F. W. MEINECKE}

\section{EXCITABILITY OF MOTOR NEURONES IN SPINAL SHOCK IN MAN: Diamantopoulos, E. \& Zander Olsen, P. (1967). F. Neurol. Neurosurg. Psychiat. 30,427 .}

In Io patients with spinal shock the action potentials accompanying the ankle jerks, the single maximal H-reflex, and the recovery of the test H-reflex after a conditioning stimulus were examined.

One of four days after the onset of spinal shock the ankle jerks were absent or severely depressed whereas single H-reflexes were normal or only slightly reduced. This suggests normal motor neurone excitability to a single afferent volley, and the reduction of the ankle jerk is considered to be due to decreased fusimotor activity. On the other hand, the recovery of the H-reflex after a conditioning stimulus was severely depressed. This indicates a depressed excitability of interneurones in addition to the reduced fusimotor activity.

One to four weeks after the onset of spinal shock ankle jerks were still somewhat depressed, indicating a persisting impairment of fusimotor activity. The recovery of the H-reflex to a conditioning stimulus was normal.

Two to three months after the onset of the spinal shock the ankle jerks were hyperactive and the action potentials accompanying them had increased to the level of H-reflexes. The recovery of the H-reflex after a conditioning stimulus was faster than in normals indicating increased central excitability.

The temporary reflex depression distal to spinal cord lesion can be due to depressed excitability of motor neurones and interneurones at segmental level, and/or to decrease of fusimotor activity. In man, early in spinal shock the ankle jerk (AJ) was severely depressed or absent whereas the electrically evoked H-reflex was slightly or not affected, suggesting depression of fusimotor activity.

Maximal AJ was elicited manually with a triggering hammer. For $\mathrm{H}$-reflex, stimuli were rectangular pulses $0.7 \mathrm{~m} . \mathrm{sec}$. applied to post tibial nerve. The action potentials associated with $\mathrm{AJ}, \mathrm{H}$-reflex and direct motor responses were recorded every Io sec. Responses were expressed as percentages of direct motor response (M) (as $J / M$ and $\mathrm{H} / \mathrm{M})$. The interval between conditioning and test stimuli was increased from I m.sec. to $4 \mathrm{sec}$. in 24 steps. $\mathrm{H} / \mathrm{M}$ was plotted against intervals. One to four days after lesions there was flaccid paralysis and absent deep reflexes. After one to four weeks deep reflexes had returned, after two to three months spasms and brisk reflexes.

N. C. Mehra 
SPINAL CORD EMBOLISM: Wolman, L. \& Bradshaw, P. (1967). F. Neurol. Neurosurg. Psychiat. 30, 446.

A clinical-pathological study of two patients with spinal cord embolism is described. In the first, the embolic material originated in severe eroding atheroma of the aorta and consisted mainly of grumous material containing some cholesterol crystals. It was found in the intercostal and lumbar arteries which were themselves free from atheroma. It is suggested that owing to the frequency of aortic atheroma compared with the infrequent finding of atheroma of spinal arteries this mechanism may be more prevalent in producing chronic ischaemic myelopathy.

In the second case the emboli consisted of fibrin originating from a mass deposited on a myxoma of the left atrium.

Several similar patterns of infarction in the spinal cord were seen in both cases. They consisted of a wedge-shaped area extending from the lateral surface, or a central area incorporating both ventral columns, but a crescent-like area in the watershed territory between anterior and posterior spinal arteries was the most typical. It would account for both the motor and sensory aspects of the syndrome.

Vascular accidents involving spinal cord are extremely rare. Damage to spinal cord from verified emboli seems to be even rarer. Two more cases have been described giving details of the nature and origin of emboli and the resultant lesion and syndrome.

Although certain features were common to both cases, nothing came to light during life by which a correct diagnosis could have been achieved.

\section{N. C. Mehra}

COMBINED DEGENERATION OF SPINAL CORD DUE TO DEFICIENCY

OF ALIMENTARY VITAMIN B 12 $_{12}$ : VerjaAl, A. \& Timmermans-VAN Den Bos, H. C. C. (1967). F. Neurol. Neurosurg. Psychiat. 30, 464.

Vitamin $B_{12}$ deficiency due to inadequate or insufficient nutrition usually causes macrocytic anaemia. Deficiency due to malabsorption caused by lack of intrinsic factor may also cause combined degeneration of cord. A case of a woman aged 68, is described in whom combined degeneration of the cord was caused by alimentary $\mathrm{B}_{12}$ deficiency.

On admission there was decubitus of the sacral region and the patient was apathetic and paranoid. She had been a vegetarian for 18 years. For three years her walking had gradually become difficult and her physical and mental condition declined until she became entirely bedridden. OE. paraplegia in flexion, arm reflexes brisk with HoffmannTrömner reflex on both hands. The knee jerks and ankle jerks were absent; PR extensor bilaterally; Abd. reflex. neg. Severe disturbance of deep sensibility and slight disturbance of pain sense below level of umbilicus. Urinary retention. $\mathrm{HCl}$ normal. $\mathrm{Hb}$ I2.5 g./ 100 ml. RBC 3 million. Megalocytosis and macrocytosis. BRC dia. 7.5 to $8.5 \mu$. MCH 4I.6 $\mu \mu \mathrm{g}$. MCV I $37 \mathrm{c} \mu$. Serum iron $22 \mathrm{mg}$./ $/ 00 \mathrm{ml}$., total Fe capacity $243 \mu \mathrm{g}$. $/ \mathrm{r} 00 \mathrm{ml}$. WBC-pronounced hypersegmentation. The bone marrow was in keeping with $\mathrm{B}_{12}$ deficiency. Serum $\mathrm{B}_{12}$ was $20 \mu \mu \mathrm{g} . / \mathrm{ml}$. Alimentary $\mathrm{B}_{12}$ deficiency was diagnosed. $\mathrm{B}_{12}$ parenterally. I000 $\mu \mathrm{g}$. thrice weekly brought no improvement.

Necropsy. Fatty degeneration of liver with central lobe necrosis, lung fibrosis bilateral, superficial defects of gastric mucosa, acute cystitis and pyelitis on right with gravel in renal pelvis and ureter. Sectioning of spinal cord showed grey discolouration in the region of the posterior column in all cervical and thoracic segments.

Microscopically. The mid-thoracic cord shows demyelinisation in white substance, especially posterior columns and fasciculus cuneatus; pyramidal, spinocerebellar and anterior pyramidal tracts are affected bilaterally. Lateral pyramidal tracts are affected in lumbar region. Myelin sheaths are greatly swollen. Numerous fat-laden sudanpositive phagocytes are seen. Axis cylinders are largely destroyed. Some roots of cauda 
equina show swelling of myelin sheaths. Tibial nerves show intense demyelinisation with numerous phagocytes laden with sudan-positive material and moderate proliferation of Schwann cells. Sacral nerves show similar but lesser changes. The anterior tibialis shows pronounced atrophy of all fibres. Endomysial fat and connective tissue is increased. Thrombi are seen in some medium sized arteries. A few intramuscular nerves show loss of myelin sheaths and increased endoneural connective tissue in axis cylinders.

\section{N. C. MEHRA}

CONTRIBUTION TO THE STUDY OF LATE CERVICAL SYRINGOMYELIC SYNDROMES AFTER DORSAL OR LUMBAR TRAUMATIC PARAPLEGiA: Rossier, A. B., Werner, A., Wildi, E. \& Berney, J. (i968). F. Neurol. Neurosurg. Psychiat. 3I, 99.

The incidence of late development of syringomyelitic syndromes at higher level after traumatic spinal cord lesions of the dorsal and lumbar regions is rare. The authors describe a boy of 15 who sustained a paraplegia at T6, following fracture of T6/8. Twelve months later, he developed thermo-analgesia between D6 and D2 and later also dissociated sensory disturbance in the left upper limb without motor disturbances. Air myelography showed considerable widening of the cervical cord from $\mathrm{C}_{3}$ to $\mathrm{C} 6$, and in addition a fracture of the spinous process of $\mathrm{C}_{7}$. Laminectomy revealed a swelling of the cord between $\mathrm{C}_{3}$ and $\mathrm{C}_{5}$, caused by a cystic cavity containing yellow non-coagulating fluid.

In discussing the pathogenesis, the authors wonder whether in this case 'an oedema of undetermined cause-insiduous and slow to progress-was the origin of the imbalance of the interstitial tissue pressure'.

INTRAMEDULLARY CYSTIC LESIONS OF THE CONUS MEDULLARIS: Nassar, S. I., Correll, T. W. \& Housepian, E. M. (1968). F. Neurol. Neurosurg. Psychiat, 31, I06.

Intramedullary cystic lesions of the conus medullaris are rare. The authors describe three patients (two men aged I6 and 22 and one woman aged 5I) who showed similar features. All three had lumbar pain and paresis of the lower limbs suspected to be tumours, intervertebral disc disease and syringomyelia respectively. Myelography showed the findings of intramedullary lesions which were interpreted as consistent with conus ependymoma. At operation localised cysts of the conus medullaris were found containing colourless cystic fluid. The protein concentration and cytological examination of the fluid as well as the biopsy of the cyst wall did not reveal an underlying tumour. Following operation the patients showed substantial improvement of motor and sphincteric functions (follow-up I 8 months and 5 years respectively).

A CASE OF EXTRADURAL SPINAL MENINGIOMA: HALlPike, J. F., \& Stanley, P. (1968). F. Neurol. Neurosurg. Psychiat. 3I, I98.

Although meningiomas are one of the most common primary spinal neoplasms they are rarely entirely extradural. The authors describe such a case of dumb-bell shaped meningioma in a man of 33 with an incomplete transverse spinal syndrome below T6. Chest X-ray showed soft-tissue mass with erosion of lower border of the right sixth rib posteriorly. Myelography showed displacement of the cord to the left at T6. At operation an encapsulated vascular tumour was found entirely extradural and extending through the intervertebral foramen into the thorax. Two weeks later at thoracotomy a full extrapleural resection of the thoracic portion of the tumour was carried out. Considerable recovery of the symptomatology following operation. 
CALCIFIED AND OSSIFIED PLAQUES OF THE SPINAL ARACHNOID MEMBRANES: KNoblich, R., \& Olsen, B. S. (I966). F. Neurosurg. 25, 275.

The relationship of calcified and ossified plaques within the spinal arachnoidea and spinal symptomatology was examined in 217 cases post-mortem (I 32 male and 85 female). Single plaques of $2 \mathrm{~mm}$. diameter and less than I mm. thickness were found in 24 per cent., single small ones up to $3 \mathrm{~mm}$. in diameter in 44.9 per cent. Multiple small and large plaques were observed in I7 per cent. and larger confluent ones in 13.9 per cent. Predilection places were the lower dorsal and lumbar areas. None of the patients showed clinically spinal symptoms which could have been caused by plaques. The patients were suffering from chronic renal disease, uraemia, carcinomatosis, metastasis and severe atherosclerosis.

According to the authors these plaques originate from accumulation of meningeal cells and seem to be an analogy to Pachionic granulations.

LE CHORDOME DE LA COLONNE CERVICALE (THE CORDOMA OF THE CERVICAL SPINE): Brihaye, T., Teannart, L., Berben, T., LustmanMarechal, T., \& Gompel, C. (I966). Acta neurochir. I5, 285.

This is a report of a case of a large cordoma of $\mathrm{C}_{4} / 5$ cervical vertebrae developing over a three-year period. X-ray showed the vertebral bodies to be relatively intact as compared with the marked destruction of the massa lateralis. Vertebral angiography revealed signs of a process of non-specific vascularisation. The development of the tumour within the soft tissues of the neck is important for the differential diagnosis of malignant tumours of the vertebral column. The authors suggest radiotherapy prior to radical surgical removal.

\section{Guttmann}

\section{THE STOKE MANDEVILLE GAMES: Sir Ludwig Guttmann (1967). Abbot- tempo, 3, I.}

Sport demands continuous training. It interrupts monotony in hospital and prevents the spinal paraplegic from resigning into isolation. It represents an essential and indispensable complement to the conventional methods of physiotherapy. It helps to overcome the physical defects and to restore psychological equilibrium and self-confidence. Moreover, through the medium of sport society at large becomes aware of the capabilities of the disabled in a wheelchair. More than I 5 types of sports events are being practised by spinal paraplegics. In 1948, Sir Ludwig Guttmann founded the Stoke Mandeville Games for the Paralyzed, which in 1952 became an annual international sports festival, which in 1960 and 1964 followed the Olympic Games in Rome and Tokyo respectively. There is a steady improvement of the standard of performances in the individual sports. Moreover, these international sports events help to promote better understanding and friendship amongst nations. Society had responded to this achievement with admiration and practical help. Friendship, Unity and Sportsmanship are the ideals of this unique sports movement which is symbolised by three intertwined wheels of a wheelchair encircling the Globe.

F. W. MEINECKE

\section{ERRATUM}

IN the last issue of the journal (I968, Vol. 6, p. 57), under 'Abstracts from Other Journals', the reference to a paper by S. Lipton should have read 'Br. med. F., I968, 2, 210'. It is regretted that the wrong volume number was given. 
DRUCKGESCCHWÜRE-KEIN ÄRZTLICHES PROBLEM? (PRESSURE SORES-NO MEDICAL PROBLEM?): HEFTNER, E. (I967). Munch. med. Wschr. I09, I868.

Pressure sores develop mainly during the first two weeks following admission to hospital. The causes are impairment of normal mobility of the patient resulting in cutaneous irritation, thrombosis and ischaemia. There are various reasons for the impairment of mobility: semi-consciousness, fixed dressings, paralysis, etc. Pressure always plays the main role. For decompression sorbo-rubber mattresses, air cushions, silicone-gel cushions and turning beds are employed. Sheepskin proved an ideal undersheet. Dangers and counter measures are presented in tables by the author. Co-operation between doctor and nursing personnel is essential for the prevention of pressure sores. Intensive and detailed guidance of the personnel regarding special dangers in the individual case are of decisive importance.

\section{F. W. MEINECKE}

\section{SOFORT-UND FRÜHBEHANDLUNG TRAUMATISCHER QUERSCHNITTS- LÄHMUNGEN (IMMEDIATE AND EARLY TREATMENT OF TRAU- 20. Orthop., I03, 512.}

The early treatment lasts for two to three months following injury. For the treatment of the fracture according to the author, an 'active' procedure is indicated in the majority of cases. In cases with incomplete paralysis the principles are closed reduction or operation. Closed reduction is preferable to laminectomy without reduction, but laminectomy can be carried out in the early stage provided it is followed by posterior fixation. Reduction should be carried out in every case of dislocation. In complete lesions reduction and stabilisation is indicated to achieve stability of the spine for the later rehabilitation. In cervical injuries anterior fusion as recommended by Cloward is accepted provided the posterior parts of the vertebrae are stabilized. Otherwise posterior fixation or anterior metalosteosynthesis of the vertebral body must be done in addition. In cases of thoracic and lumbar injuries progression of paraplegia represents an absolute indication for decompressive operation.

The dangers in the early stage are pneumonia necessitating tracheostomy and assisted respiration and hyperthermia as the result of disturbed temperature regulation. Pressure sores are signs of faulty treatment or inadequate nursing.

Plaster of Paris is deprecated. Two-hourly turning on turning beds or sorbo-rubber mattresses is necessary. Ventral or dorsal shells of Plaster of Paris may be employed as emergency measures (Notlösung), but only in combination with two hourly turning. Pressure sores need plastic covering in the majority of cases.

Intermittent catheterisation is only possible in special centres with skilled personnel, otherwise indwelling permanent catheterisation is recommended. The value of tidal drainage is uncertain.

For the treatment of early paralytic ileus the author recommends hot water bottles, prostigmine and small enemas.

For stabilisation of the metabolism two blood-or plasma-transfusions per week and high protein diet are recommended.

The treatment of spasms is mainly operative.

The early treatment can be carried out in specialised accident hospitals; however, the physical rehabilitation and social reintegration of the patient should be the prerogative of specialised centres.

This paper will have to be read with criticism. This applies in particular to the very 'active' approach to the fractures and dislocations by the author, furthermore to the employment of plaster shells as 'Notbehelf' (emergency measure), the application of 
hot-water bottles applied to the paralysed part of the body and the management of the paralysed bladder in the early stage by permanent indwelling catheterisation.

One has to accept at present, the division of the immediate and early management and the physical and social rehabilitation later, in most European countries because of the incomplete local facilities available. However, there is no doubt that spinal centres where comprehensive management of these patients from the start and throughout all stages should be made available. The professional and industrial training can follow later in specialised institutions.

\section{F. W. MEINECKE}

PRINCIPLES OF INITIAL TREATMENT OF TRAUMATIC PARAPLEGICS AND TETRAPLEGICS: Festschrift in honour of 8oth birthday of Sir Harry Platt Bt. Aspects of Rehabilitation: Sir Ludwig Guttmann. Published by the National Fund for Research into Crippling Diseases. 1967, p. I8-28

The immediate and early management of traumatic paraplegia and tetraplegia following fractures and fracture-dislocation of the spine is discussed in the light of the author's experience of 2500 patients.

The management should start at the place of accident. Details of first-aid and transport of the injured by ambulance or by air are given. It is stressed that by certain first-aid measures additional damage to the spinal cord may be avoided. Dislocations and fracturedislocations may be reduced immediately by proper handling and adequate technique before the patient's transfer to hospital.

Immediate or early transfer to a spinal injuries centre, where the best facilities for dealing with all the aspects of paraplegia and tetraplegia exist, is strongly recommended.

The author rejects immediate or early surgical procedures such as decompressive or exploratory laminectomy as well as open reduction and fixation by any method, in particular by metal plates. Anterior or posterior fusions in cervical lesions are also considered as unnecessary. The extremely rare exceptions which justify early operation are described.

The method of choice of immediate and early management adopted and developed at Stoke Mandeville is postural reduction which has proved highly successful in both simple stable compression fractures and unstable fracture-dislocations. Details of the technique are described. In fractures and fracture-dislocations of the cervical spine resulting in complete or incomplete tetraplegia postural reduction is combined with skull traction.

Attention is drawn to a new electrically controlled turning and tilting bed which greatly facilitates the management of these patients. This bed is provided with a special head-traction unit introduced by the author which allows turning the tetraplegic from the supine to the lateral position without removing the weight during turning.

In discussing the immediate and early management of the paralysed bladder, attention is drawn to an I I years' study of 476 patients admitted within the first I4 days after injury, the majority within the first 48 hours. Intermittent catheterisation using the author's 'non-touch' technique has proved most effective in preventing early infection of the urinary tract and is considered as the method of choice in the early stages of paraplegia and tetraplegia. This catheterisation in the early stages of bladder paralysis should be carried out by an experienced medical officer and should not be left to the nursing staff. Suprapubic drainage as revived in recent years by Lapides et al. in the United States as cutaneous vesicostomy for the early management of the paralysed bladder is strongly rejected by the author. 